\title{
ArRoz Tolerante a Imidazolinonas: Banco de Sementes De ARroZ-Vermelho e FluXo GÊNico ${ }^{1}$
}

\author{
Imidazolinone-Tolerant Rice: Red Rice Seed Bank and Gene Flow
}

MARCHESAN, E. ${ }^{2}$, MASSONI, P.F.S. ${ }^{3}$, GROHS, M. ${ }^{4}$, VILLA, S.C.C. ${ }^{5}$, AVILA, L.A. ${ }^{6}$ e ROSO, R. ${ }^{7}$

\begin{abstract}
RESUMO - Este trabalho teve por objetivo avaliar a rotação do sistema Clearfield ${ }^{\circledR}$ de arroz irrigado com o sistema convencional na evolução do banco de sementes e no surgimento de biótipos de arroz-vermelho resistentes ao grupo químico das imidazolinonas. O delineamento experimental foi de blocos ao acaso, em esquema bifatorial $(2 \times 4)$ com quatro repetições. $\mathrm{O}$ fator A correspondeu aos sistemas de manejo utilizados (Clearfield ${ }^{\circledR} \mathrm{x}$ convencional) e constou da sucessão/rotação entre arroz não tolerante a imidazolinonas (convencional), variedade IRGA 417, e arroz tolerante a imidazolinonas, IRGA 422 (Clearfield ${ }^{\circledR}$ ). O fator D foi composto pela variação ao longo do tempo entre o sistema convencional e o Clearfield ${ }^{\circledR}$. A utilização do sistema Clearfield ${ }^{\circledR}$ proporciona redução do banco de sementes após três anos de utilização, porém não elimina todas as sementes de arroz-vermelho do solo. O cruzamento entre o arroz-vermelho e o arroz cultivado aumenta à medida que há maior infestação da área, chegando a 2,9\% após quatro cultivos.
\end{abstract}

Palavras-chave: biótipos resistentes, Oryza sativa, sistema Clearfield ${ }^{\circledR}$

\begin{abstract}
The objective of this study was to evaluate the rotation of the irrigated rice Clearfield $\mathbb{R}$ system with the conventional system in the evolution of the seed bank and the emergence of red rice biotypes resistant to the imidazolinone chemical group. The experiment was arranged in a randomized block design in a factorial scheme $(2 x 4)$ with 4 replications. The first factor was constituted of the management systems used (Clearfield ${ }^{\circledR} x$ conventional) which consisted of the succession/rotation between the rice not tolerant to imidazoline, variety IRGA 417 (conventional), and the rice tolerant to imidazolinone, variety IRGA 422 CL (Clearfield ${ }^{\circledR}$ ). The D factor was constituted by the variation between the conventional and the Clearfield ${ }^{\circledR}$ systems, overtime. The use of the Clearfield ${ }^{\circledR}$ system provides a reduction of the seed bank after three years of use; however, it does not remove all the red rice seeds from the soil. The crossing between red rice and cultivated rice increases with the increase of infestation, reaching $2.9 \%$ after four crops.
\end{abstract}

Keywords: resistant biotypes, Oryza sativa, Clearfield system ${ }^{\circledR}$.

\section{INTRODUÇÃO}

O banco de sementes representa um papel ecológico importante no suprimento de novos individuos para as comunidades vegetais. No entanto, em se tratando de plantas daninhas, ele constitui um sério problema na atividade agrícola, pois garante infestações de plantas daninhas por longos períodos, mesmo quando é impedida a entrada de novas sementes na área.

Apesar de constituir-se em um grande depósito de sementes, a composição florística do solo agrícola, em determinado momento, não representa o potencial real de infestação, já

Recebido para publicação em 7.4.2011 e aprovado em 17.6.2011.

2 Professor, Doutor, Dep. de Fitotecnia, Universidade Federal de Santa Maria - UFSM, Av. Roraima, 1000, 97105-000 Santa Maria-RS, Brasil, <emarchezan@terra.com.br>; ${ }^{3}$ Engo-Agr ${ }^{\circ}$., M.Sc., UFSM, <pfmass@ hotmail.com>; ${ }^{4}$ Eng $^{\circ}-$ Agr $^{\circ}$., estudante de pós-graduação, UFSM, <maragrohs@yahoo.com.br>; ${ }^{5}$ Eng으-Agro ${ }^{\circ}$, M.Sc., Empresa Rice Tec, <silviovilla@msn.com>; ${ }^{6}$ Professor, Doutor, Dep. de Fitossanidade, Universidade Federal de Pelotas - UFPel, <laavilabr@gmail.com>; 7 Aluno de graduação do Curso de Agronomia, UFSM, <rodrigoroso@yahoo.com.br> 
que certas espécies necessitam de condições especiais para a quebra de dormência e posterior germinação. Nesse contexto enquadra-se o arroz-vermelho (Oryza sativa), uma das mais importantes plantas daninhas em áreas produtoras de arroz do mundo (Fleck et al., 2008), visto que sua presença em lavouras comerciais, além de reduzir a produtividade e qualidade, aumenta o custo de produção decorrente do acréscimo de práticas adicionais de controle. O dificil controle do arroz-vermelho deve-se, em parte, ao seu degrane precoce e também à sua dormência no solo (Noldin et al., 2006), pois suas sementes se encontram aptas a germinar nove dias após a floração, apresentando viabilidade de $20 \%$ (FAO, 2003). Com o degrane, as sementes de arroz-vermelho enriquecem o banco de sementes, com biótipos de diferentes comportamentos em relação à germinação e emergência. Assim, parte das sementes que não germinam imediatamente pode permanecer por longos períodos no solo, aguardando as condições necessárias para sua germinação.

A distribuição das sementes no perfil do solo é influenciada pela frequência de preparo do solo, o que pode dar origem a bancos de sementes persistentes no solo (Ikeda et al., 2007). Com relação a isso, Smith Junior (1992) afirma ter encontrado sementes de arrozvermelho viáveis no solo após 12 anos. A capacidade de permanência das sementes de arroz-vermelho no solo, além de dificultar o controle dessa invasora, também interfere no surgimento de resistência a herbicidas, alterando ao longo do tempo a composição específica (seleção de flora) ou a frequência gênica de uma espécie (seleção de biótipos resistentes).

Após várias décadas de busca de alternativas para o controle seletivo do arroz-vermelho, desenvolveram-se genótipos de arroz tolerantes a herbicidas do grupo químico das imidazolinonas, através de mutação induzida (Croughan, 1998). O uso de herbicidas em genótipos com essa característica constitui-se em uma estratégia eficiente para o controle de arrozvermelho. Contudo, há relatos de que o controle total de arroz-vermelho dificilmente alcança $100 \%$, permitindo o escape de plantas, o que possibilita o surgimento de arroz-vermelho resistente ao herbicida utilizado no sistema
Clearfield ${ }^{\circledR}$. Segundo Villa et al. (2006), o fluxo gênico ocorre quando há controle deficiente e as plantas remanescentes florescem simultaneamente, o que pode causar o surgimento de biótipos de arroz-vermelho tolerantes a imidazolinonas, reduzindo a longevidade dessa tecnologia. Nesse sentido, a hipótese do trabalho é de que a utilização do sistema Clearfield ${ }^{\circledR}$ controla o arroz-vermelho e atua na redução do banco de sementes, diminuindo a possibilidade de cruzamento natural.

Assim, o objetivo deste estudo foi avaliar a rotação do sistema Clearfield ${ }^{\circledR}$ com o sistema convencional de cultivo de arroz irrigado na evolução do banco de sementes e no surgimento de biótipos de arroz-vermelho resistentes ao grupo químico das imidazolinonas.

\section{MATERIAL E MÉTODOS}

O experimento foi instalado em campo em área de várzea sistematizada, sendo conduzido nos anos agrícolas de 2004/05, 2005/06, 2006/07 e 2007/08. O solo é classificado como Planossolo Háplico Eutrófico arênico (Embrapa, 2006). O local se caracteriza por apresentar clima subtropical úmido, de fórmula climática Cfa, segundo a classificação de Köppen, com precipitação pluvial média de $1.616 \mathrm{~mm}$ ao ano e altitude de $95 \mathrm{~m}$.

O delineamento experimental utilizado foi de blocos ao acaso, em esquema bifatorial $(2 \times 4)$ com quatro repetições, tendo parcelas de $5 \times 6 \mathrm{~m}\left(30 \mathrm{~m}^{2}\right)$. O fator A correspondeu aos sistemas de manejo utilizados, formados pela combinação dos sistemas Clearfield ${ }^{\circledR}$ e convencional. O sistema convencional caracterizouse pela semeadura de um genótipo de arroz não tolerante às imidazolinonas, IRGA 417; portanto, não foi utilizado nenhum manejo químico para o controle do arroz-vermelho. O sis-

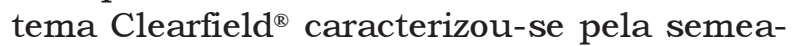
dura de genótipo tolerante às imidazolinonas, IRGA 422CL, no qual foi aplicada a mistura formulada de imazethapyr $\left(75 \mathrm{~g} \mathrm{~L}^{-1}\right)+$ imazapic $\left(25 \mathrm{~g} \mathrm{~L}^{-1}\right)$, produto comercial Only ${ }^{\circledR}$, na dose de $1 \mathrm{~L} \mathrm{ha}^{-1}$, visando ao controle de arrozvermelho. A aplicação do herbicida foi realizada em pós-emergência (POS), aos 14 dias após a emergência (DAE) do arroz, com pulverizador costal pressurizado com $\mathrm{CO}_{2}$, quando as plantas do arroz cultivado encontravam-se no estádio 
V4 (Counce et al., 2000), e as de arrozvermelho, em V5. A vazão utilizada foi de $150 \mathrm{~L} \mathrm{ha}^{-1}$, com adição de $0,5 \% \mathrm{v} \mathrm{v}^{-1}$ de óleo mineral emulsionável.

O fator D foi composto pela variação ao longo do tempo dos sistemas convencional e Clearfield ${ }^{\circledR}$, conforme apresentado na Tabela 1.

Para homogeneizar o banco de sementes de arroz-vermelho, na primeira safra (2004/ 05), distribuiu-se a lanço e incorporou-se, um dia antes da semeadura do arroz, a quantidade de $200 \mathrm{~kg} \mathrm{ha}^{-1}$ de sementes de arroz-vermelho, obtendo-se o banco de sementes inicial de 403 sementes de arroz-vermelho $\mathrm{m}^{-2}$ na profundidade de $0-1 \mathrm{~cm}$ e de 418 na profundidade de $1-5 \mathrm{~cm}$, alcançando uma população média emergida de 260 plantas de arroz-vermelho $\mathrm{m}^{-2}$. No primeiro ano, o solo foi preparado através de duas gradagens, enquanto nos demais anos foi utilizada a semeadura direta.

A coleta de solo para estimar o número de sementes de arroz-vermelho existente na área foi realizada através de cinco subamostras por parcela principal, com auxílio de um trado cilindrico de metal, de $10 \mathrm{~cm}$ de diâmetro, na profundidade de $0-1$ e $1-5 \mathrm{~cm}$, no período da entressafra do arroz. O número de sementes por metro quadrado nas parcelas foi determinado em razão da área do trado tubular de coleta de solo e multiplicado pelo número de subamostras coletado por parcela, tendo-se uma área total de amostragem de $0,04 \mathrm{~m}^{2}$ por parcela.

Após a coleta, as sementes de arroz-vermelho foram retiradas do solo através de lavagem das amostras em água corrente, sob peneiras de $2 \mathrm{~mm}$. Para a análise, os dados de número de sementes de arroz-vermelho coletados do solo foram transformados em $y t=\sqrt{(y+0,5)}$, para normatização de sua distribuição. Posteriormente elas foram submetidas à análise de variância, e suas médias, comparadas entre si pelo teste de Tukey $(\leq 0,05)$.

Para determinação do fluxo gênico entre arroz-vermelho e arroz tolerante a imidazolinonas, foram coletadas todas as panículas das plantas de arroz-vermelho não controladas pelo herbicida. Foram coletadas e analisadas 4.637, 18.000 e 4.532 sementes, nas safras de 2004/ 05, 2005/06 e 2006/07, respectivamente sementes essas oriundas dos tratamentos que receberam alguma vez, entre os anos, a aplicação do herbicida. O fluxo gênico foi determinado através do número de sementes de arroz-vermelho germinadas após terem sido submetidas à embebição em imazethapyr a $0,5 \%$ e semeadas em papel germitest, as quais foram mantidas em temperatura de $25^{\circ} \mathrm{C}$ em câmara de germinação, até o momento das avaliações, que ocorreram aos quatro e sete dias após a semeadura, conforme metodologia descrita por Silva et al. (2007). Foram consideradas oriundas de cruzamento as plantas que germinaram normalmente.

\section{RESULTADOS E DISCUSSÃO}

Na Figura 1 encontra-se a evolução do banco de sementes verificada nas diferentes sequências entre os sistemas de cultivo e os anos estudados. Na Figura 1A, no sistema 1 (rotação entre convencional (conv.), Clearfield ${ }^{\circledR}(\mathrm{CL})$, conv., conv.), constata-se que, ao final dos quatro anos agrícolas, o banco de sementes aumentou cerca de oito vezes (3.438 sementes $\mathrm{m}^{-2}$ ) em relação ao banco inicial (403 sementes $\mathrm{m}^{-2}$ ), na profundidade de $0-1 \mathrm{~cm}$. Na comparação entre os anos, houve aumento significativo no banco de sementes no final do primeiro ano (1.368 sementes $\left.\mathrm{m}^{-2}\right)$

Tabela 1 - Combinação dos tratamentos, em que o fator A constitui a rotação entre o cultivo do arroz convencional e o do arroz do sistema Clearfield ${ }^{\circledR}$ e o fator D, a distribuição durante os anos agrícolas. Santa Maria-RS, 2011

\begin{tabular}{|c|c|c|c|c|}
\hline Sistema & $2004 / 05$ & $2005 / 06$ & $2006 / 07$ & $2007 / 08$ \\
\hline Sistema 1 & Convencional & Clearfield $^{(\mathbb{R}}$ & Convencional & Convencional \\
\hline Sistema 2 & Clearfield $^{(\mathbb{B}}$ & Convencional & Convencional & Convencional \\
\hline Sistema 3 & Clearfield $^{(B)}$ & Clearfield $^{(\mathbb{R}}$ & Convencional & Convencional \\
\hline Sistema 4 & Clearfield $^{(\circledR)}$ & Clearfield $^{\circledR}$ & Clearfield $\left.^{(}\right)$ & Convencional \\
\hline
\end{tabular}




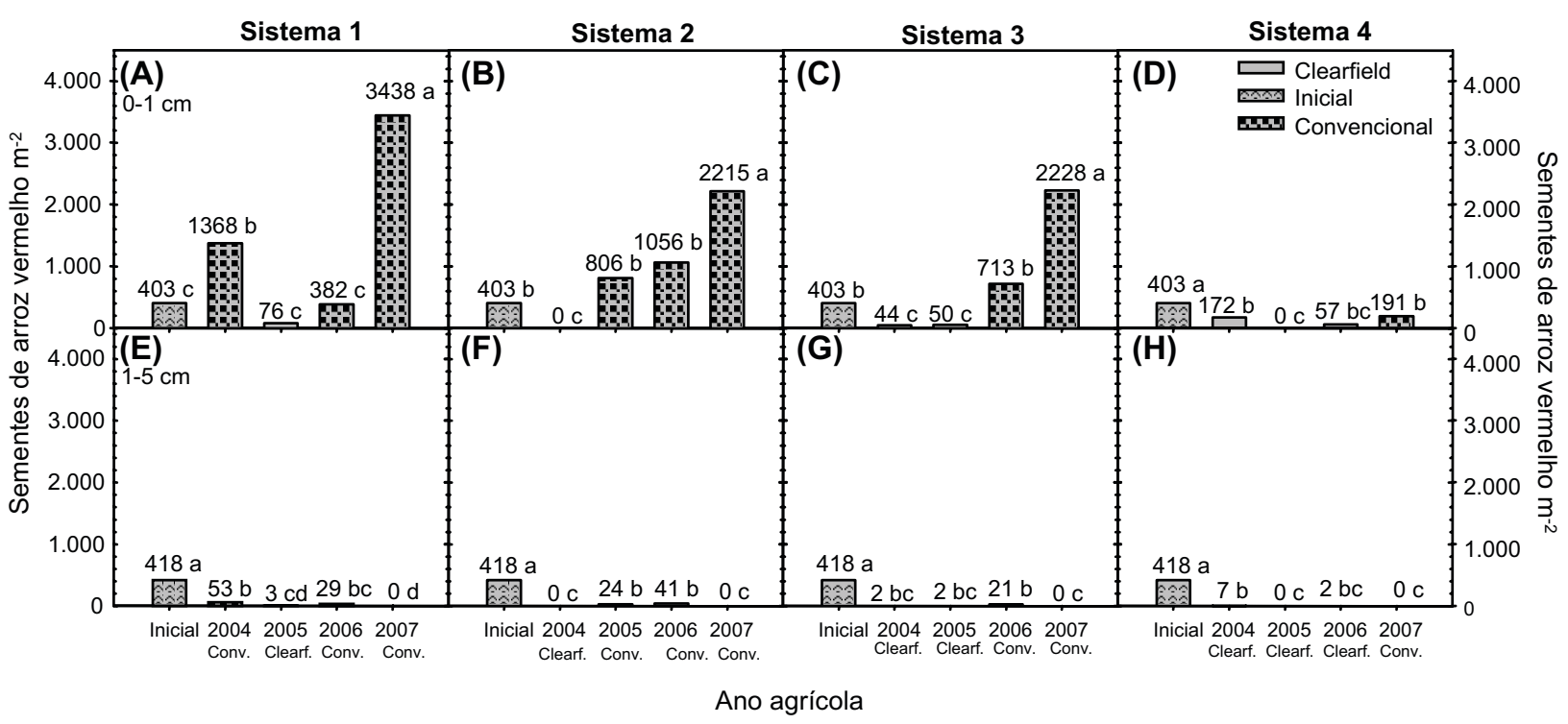

Figura 1 - Número de sementes de arroz-vermelho $\mathrm{m}^{-2}$ no solo, em diferentes sequências de cultivo com o sistema Clearfield ${ }^{\circledR}$ e convencional, nas profundidades de 0-1 cm (A-D) e 1-5 cm (E-H). Santa Maria-RS, 2011.

ao ser adotado o sistema convencional. Por outro lado, com a utilização do sistema Clearfield ${ }^{\circledR}$, esse número foi reduzido para 76 sementes $\mathrm{m}^{-2}$, no ano subsequente. Mesmo com a utilização desta tecnologia, o controle não foi totalmente efetivo - evidenciado pela presença de sementes de arroz-vermelho no solo ao final da safra. Segundo Santos et al. (2007) e Villa et al. (2006), o controle muitas vezes não alcança $100 \% \mathrm{em}$ razão das condições ambientais para a aplicação e da maneira como esta é executada.

No entanto, de maneira geral, o uso do sistema Clearfield ${ }^{\circledR}$ promove redução no número de sementes $\mathrm{m}^{-2}$, o que não significa a viabilização do cultivo no sistema convencional no ano seguinte, pois o retorno com o sistema convencional por dois anos consecutivos elevou significativamente o número de sementes de arroz-vermelho por metro quadrado (sistema 1). Essa situação é indesejável na lavoura, pois, de acordo com Smith Junior et al. (1981), a presença de cinco plantas de arrozvermelho $\mathrm{m}^{-2}$ causa redução de $22 \%$ na produtividade.

$\mathrm{Na}$ profundidade de $1-5 \mathrm{~cm}$ (Figura $1 \mathrm{E}$ ), nesse mesmo sistema 1 , houve decréscimo do número de sementes encontradas, independentemente do manejo utilizado. Esse resultado é em função de a semeadura ter sido realizada sem o revolvimento do solo e, consequentemente, sem a incorporação das sementes que degranaram nos anos anteriores ao perfil do solo.

No sistema 2 (CL, conv., conv., conv.) (Figura 1B), a utilização do sistema Clearfield ${ }^{\circledR}$ logo após a avaliação inicial reduziu o número de sementes de 403 para 0 semente $\mathrm{m}^{-2}$, o que demonstra que o grau de infestação inicial tem influência direta na eficiência do sistema Clearfield ${ }^{\circledR}$. Contudo, o retorno ao sistema convencional causou crescimento gradual do número de sementes por metro quadrado, ocasionando a reinfestação da área. Para a profundidade de 1-5 cm (Figura 1F), o comportamento foi semelhante ao do sistema anterior: o banco de sementes foi diminuído nessa profundidade, devido à falta de preparo (mobilização) da área.

O sistema 3 (Figura 1C) foi semelhante aos demais sistemas quanto à utilização do sistema Clearfield $^{\circledR}$, porém, mesmo com uma população inicial baixa (403 sementes $\mathrm{m}^{-2}$ ), não houve $100 \%$ de controle das plantas de arroz-vermelho, sendo detectadas sementes dessa cultura no banco de sementes mesmo com a utilização consecutiva por dois anos agrícolas do Clearfield ${ }^{\circledR}$. Com a volta ao sistema convencional houve incremento no banco de sementes de arroz-vermelho na profundidade de $0-1 \mathrm{~cm}$ - comportamento semelhante 
ao dos sistemas 1 e 2 após o uso do sistema Clearfield ${ }^{\circledR}$. No último ano de avaliação (2007) dos sistemas 1,2 e 3 , todos apresentaram maior número de sementes de arroz-vermetho por metro quadrado, diferindo dos demais anos de avaliação.

Por outro lado, no sistema 4 (Figura 1D), onde se utilizou por três anos consecutivos o sistema Clearfield ${ }^{\circledR}$, o segundo e terceiro anos apresentaram as menores quantidades de sementes de arroz-vermelho por metro quadrado, diferindo da avaliação inicial. O sistema 4 foi o único que apresentou o menor número de sementes $\mathrm{m}^{-2}$ em relação ao banco inicial de sementes no último ano de avaliação, demonstrando a necessidade de controle químico do arroz-vermelho por safras subsequentes e que essa tecnologia é eficiente em reduzir o banco de sementes de arroz-vermelho. Todavia, segundo os resultados, ocorreu escape de plantas de arroz-vermelho, o que possibilita o surgimento de arroz-vermelho resistente ao herbicida usado no sistema Clearfield ${ }^{\circledR}$; mesmo que a época de aplicação e a dose sejam adequadas, é dificil obter $100 \%$ de controle do arrozvermelho, o que compromete a tecnologia, se for utilizada de forma contínua na mesma área.

Os resultados obtidos neste trabalho, representados no sistema 3, demonstram que dois anos não são suficientes para eliminar o arroz-vermelho da área, estando coerentes com a recomendação para uso deste sistema, propondo que, após dois anos de Clearfield ${ }^{\circledR}$,é necessária a rotação com outra cultura ou o pousio da área. Além da possibilidade de cruzamento natural entre o arroz-vermelho produto do escape de controle e o arroz cultivado, há ainda o potencial problema de injúrias causadas às culturas sensiveis ao efeito residual do herbicida no solo (Villa et al., 2006; Marchesan et al., 2010). Assim, o sistema Clearfield ${ }^{\circledR}$ está relacionado também com o possível fluxo gênico com os escapes de controle, sendo pertinente relacionar o banco de sementes com a taxa de cruzamento do arroz-vermelho com o arroz cultivado.

Na Figura 2 é apresentada a comparação entre os sistemas para o último ano de cultivo (2007), na profundidade de $0-1 \mathrm{~cm}$. A profundidade de 1-5 em não foi apresentada, em razão da inexistência de sementes nos quatro sistemas.

Entre os sistemas, o uso subsequente do sistema Clearfield ${ }^{\circledR}$ por três anos com retorno ao convencional (sistema 4) é o mais eficiente em reduzir o número de sementes de arroz-vermelho. Os sistemas que utilizaram a tecnologia Clearfield ${ }^{\circledR}$ por até dois anos consecutivos não foram eficientes em termos de redução do banco de sementes de arroz-vermelho, pois ele ainda apresentaram mais de 2.000 mil sementes $\mathrm{m}^{-2}$ no banco de sementes na profundidade $0-1 \mathrm{~cm}$. No entanto, é importante salientar que utilização do sistema Clearfield ${ }^{\circledR}$ por três anos consecutivos, embora tenha reduzido substancialmente o banco de sementes, não elimina por completo essa invasora, já que se observou a presença de sementes.

Para que a efetividade do herbicida seja máxima, há necessidade de duas aspersões de imazethapyr: uma em pré-emergência e outra em pós-emergência (Villa et al., 2006). À medida que a aplicação é atrasada, a eficiência de controle diminui, sobretudo em áreas com alta infestação. A eficiência do controle de arroz-vermelho com o uso do imazethapyr varia, entre outros fatores, com a dose, a época de aplicação do produto e, principalmente, o manejo da irrigação. Embora o controle de arroz-vermelho através do uso desses herbicidas seja eficiente, geralmente não chega a $100 \%$.

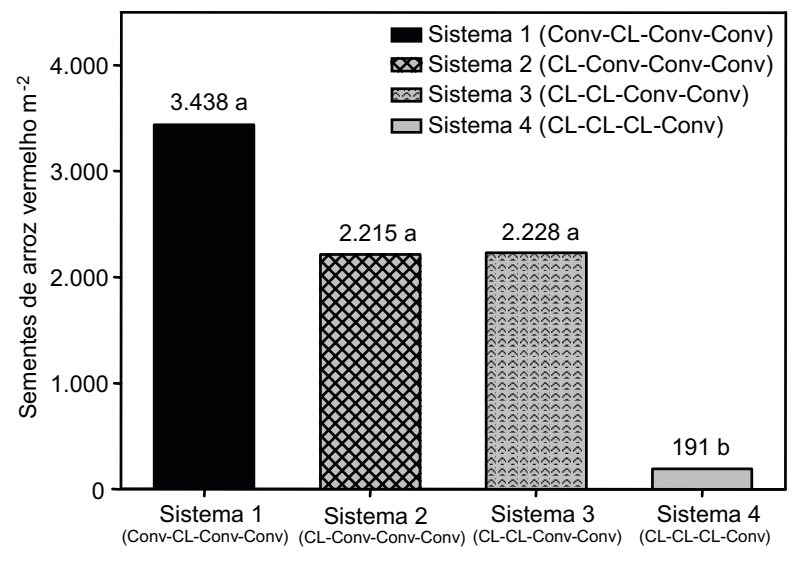

Figura 2 - Comparação entre os bancos de sementes ao final de quatro safras (2006/07) em função de diferentes sequências de cultivo na profundidade de $0-1 \mathrm{~cm}$, entre os sistemas de cultivo convencional e Clearfield $^{\circledR}$. Santa Maria-RS, 2010. 
O sistema 3 seria a representação do que é recomendado, ou seja, que após dois anos de Clearfield ${ }^{\circledR}$ é necessária a rotação com outra cultura ou o pousio da área. Contudo, os resultados obtidos neste trabalho demonstram que dois anos não são suficientes para eliminar o arroz-vermelho da área. Além da possibilidade de cruzamento natural entre o arrozvermelho produto do escape de controle e o arroz cultivado, há ainda o potencial problema de injúrias causadas às culturas sensíveis ao efeito residual do herbicida no solo (Villa et al., 2006; Marchesan et al., 2010). Assim, o sistema Clearfield ${ }^{\circledR}$ está relacionado também com o possivel fluxo gênico com os escapes de controle, sendo pertinente então relacionar o banco de sementes com a taxa de cruzamento do arroz-vermelho com o arroz cultivado.

Na Tabela 2 consta a taxa de cruzamento entre o arroz-vermelho e o cultivado, o número de sementes avaliadas e também o número de sementes de arroz-vermelho tolerante em cada ano agrícola.

Observa-se que houve aumento no número de sementes tolerantes no decorrer dos anos avaliados. Esse fato reflete o aumento da taxa de cruzamento entre o primeiro e o terceiro ano, apresentando no terceiro ano o valor de $2,9 \%$. Confirmando isso, vários autores, como Messeguer et al. (2004), Rajguru et al. (2005) e Villa et al. (2006), demonstraram a possibilidade de cruzamentos naturais entre o arroz comercial e o arroz-vermelho, bem como a ocorrência de plantas daninhas resistentes ao herbicida, com a consequente perda dessa ferramenta para o controle químico de arrozvermelho. Por ser o arroz uma planta autógama com taxa de fecundação inferior a $1 \%$,

Tabela 2 - Número de sementes avaliadas, número de sementes de arroz-vermelho tolerante e taxa de cruzamento obtidos nos anos agrícolas de 2004/05, 2005/06 e 2006/07 e estimativa de sementes tolerantes no solo para o último ano de cultivo (2007), com base no banco de sementes e na taxa de cruzamento. Santa Maria-RS, 2011

\begin{tabular}{|c|c|c|c|}
\hline $\begin{array}{c}\text { Ano } \\
\text { agrícola }\end{array}$ & $\begin{array}{c}\text { Número de } \\
\text { sementes avaliadas }\end{array}$ & $\begin{array}{c}\text { Número de } \\
\text { sementes de arroz- } \\
\text { vermelho tolerantes }\end{array}$ & $\begin{array}{c}\text { Cruzamento } \\
(\%)\end{array}$ \\
\hline $2004 / 05$ & 4.637 & 3 & 0,065 \\
\hline $2005 / 06$ & 18.000 & 8 & 0,044 \\
\hline $2006 / 07$ & 4.532 & 131 & 2,9 \\
\hline
\end{tabular}

Estorinos Jr. et al. (2003) encontraram taxas de cruzamento entre o arroz cultivado e o arroz-vermelho na faixa de 0,0045 a $0,0014 \%$, dependendo do cultivar.

A variação que ocorreu na taxa de cruzamento entre o primeiro e o terceiro ano, que propiciou ao final o valor de $2,9 \%$, é reflexo da infestação de arroz-vermelho da área entre os anos, pois existem mais plantas em diferentes estádios e mais próximas, o que facilita a polinização cruzada e a viabilidade do pólen. Dessa forma, após o segundo ou terceiro ano da utilização do sistema Clearfield ${ }^{\circledR}$, é importante manter a área em pousio ou fazer a rotação com outra cultura que utilize um herbicida com outro mecanismo de ação e viabilize o controle do arroz-vermelho tolerante.

Os resultados indicam que há redução no banco de sementes após três anos de utilização do sistema Clearfield ${ }^{\circledR}$. Entretanto, isso não significa eliminação total das sementes no solo. Existe cruzamento entre o arroz-vermelho e o arroz cultivado, o qual é tanto maior quanto maior for a infestação da área.

\section{LITERATURA CITADA}

COUNCE, P. A. et al. A uniform, objective, and adaptive system for expressing rice development. Crop Sci., v. 40, n. 2 , p. $436-443,2000$.

CROUGHAN, T. P. Application of tissue culture techniques to the development of herbicide resistant rice. Louisiana Agric., v. 37, n. 1, p. 25-26, 1998

EMPRESA BRASILEIRA DE PESQUISAAGROPECUÁRIA - EMBRAPA. Centro Nacional de Pesquisa de Solos. Sistema brasileiro de classificação de solos. Rio de Janeiro: 2006. 306 p.

ESTORNINOS Jr., L. E. et al. Simple sequence repeats analysis of hybridization between IMI rice and red rice. In: SOUTHERN WEED SCIENCE SOCIETY ANNUAL MEETING, 56., 2003, Houston. Proceedings... Houston: SWSS, 2003. p. 184.

FAO. Weed management for developing countries. Addendum 1, 2003. Disponível em: <http://www.fao.org > Diversos acessos.

FLECK, N. G. et al. Competitividade relativa entre cultivares de arroz irrigado e biótipo de arroz-vermelho.

Planta Daninha, v. 26, n. 1, p. 101-111, 2008. 
IKEDA, F. S et al. Caracterização florística de bancos de sementes em sistemas de cultivo lavoura-pastagem.

Planta Daninha, v. 25, n. 4, p. 735-745, 2007.

MARCHESAN, E. et al. Carryover of imazethapyr and imazapic to nontolerant rice. Weed Technol., v. 24, n. 1, p. 6-10, 2010.

MESSEGUER, J. et al. A field study of pollen-mediated gene flow from Mediterranean GM rice to conventional rice and the red rice weed. Molec. Breeding, v. 13, n. 1, p. 103-112, 2004.

NOLDIN, J. A. Seed longevity of red rice ecotypes buried in soil. Planta Daninha, v. 24, n. 4, p. 611-620, 2006.

RAJGURU, S. N. et al. Mutations in the red rice ALS gene associated with resistence to imazethapyr. Weed Sci., v. 53, n.5, p. 567-577, 2005.
SANTOS, F. M. et al. Controle químico de arroz-vermelho na cultura do arroz irrigado. Planta Daninha, v. 25, n. 2, p. $405-412,2007$.

SILVA, M. P. et al. Detecção de sementes de arroz mutante tolerante ao herbicida imazethapyr. R. Bras. Sementes, v. 29, n. 2 , p. 130-137, 2007.

SMITH JUNIOR, R. J. Control of red rice (Orysa sativa L.) in water- seeded rice (Orysa sativa L.).Weed Sci., v. 29, n.6, p. 663-666, 1981.

SMITH JUNIOR, R. J. Red rice control. Agribus.

Worldwide, v. 1, n. 1, p. 18-23, 1992.

VILLA, S. C. C. et al. Arroz tolerante a imidazolinonas: controle do arroz-vermelho, fluxo gênico e efeito residual do herbicida em culturas sucessoras não-tolerantes.

Planta Daninha, v. 24, n. 4, p. 761-768, 2006. 